Article

\title{
Genome-Wide Identification of NBS-Encoding Resistance Genes in Sunflower (Helianthus annuus L.)
}

\author{
Surendra Neupane ${ }^{(\mathbb{D})}$, Ethan J. Andersen, Achal Neupane ${ }^{(1)}$ and Madhav P. Nepal * \\ Department of Biology and Microbiology, South Dakota State University, Brookings, SD 57007, USA; \\ surendra.neupane@sdstate.edu (S.N.); ethan.andersen@sdstate.edu (E.J.A.); achal.neupane@sdstate.edu (A.N.) \\ * Correspondence: madhav.nepal@sdstate.edu; Tel.: +1-605-688-5971
}

Received: 31 May 2018; Accepted: 20 July 2018; Published: 30 July 2018

\begin{abstract}
Nucleotide Binding Site-Leucine-Rich Repeat (NBS-LRR) genes encode disease resistance proteins involved in plants' defense against their pathogens. Although sunflower is affected by many diseases, only a few molecular details have been uncovered regarding pathogenesis and resistance mechanisms. Recent availability of sunflower whole genome sequences in publicly accessible databases allowed us to accomplish a genome-wide identification of Toll-interleukin-1 receptor-like Nucleotide-binding site Leucine-rich repeat (TNL), Coiled Coil (CC)-NBS-LRR (CNL), Resistance to powdery mildew8 (RPW8)-NBS-LRR (RNL) and NBS-LRR (NL) protein encoding genes. Hidden Markov Model (HMM) profiling of 52,243 putative protein sequences from sunflower resulted in 352 NBS-encoding genes, among which 100 genes belong to CNL group including 64 genes with RX_CC like domain, 77 to TNL, 13 to RNL, and 162 belong to NL group. We also identified signal peptides and nuclear localization signals present in the identified genes and their homologs. We found that NBS genes were located on all chromosomes and formed 75 gene clusters, one-third of which were located on chromosome 13. Phylogenetic analyses between sunflower and Arabidopsis NBS genes revealed a clade-specific nesting pattern in CNLs, with RNLs nested in the CNL-A clade, and species-specific nesting pattern for TNLs. Surprisingly, we found a moderate bootstrap support (BS $=50 \%$ ) for CNL-A clade being nested within TNL clade making both the CNL and TNL clades paraphyletic. Arabidopsis and sunflower showed 87 syntenic blocks with 1049 high synteny hits between chromosome 5 of Arabidopsis and chromosome 6 of sunflower. Expression data revealed functional divergence of the NBS genes with basal level tissue-specific expression. This study represents the first genome-wide identification of NBS genes in sunflower paving avenues for functional characterization and potential crop improvement.
\end{abstract}

Keywords: coiled coil; disease resistance; nucleotide binding site encoding genes; gene clustering; plant defense; resistance pathways; resistance to powdery mildew 8; R genes; sunflower; synteny

\section{Introduction}

Plants employ different gene families in signaling networks in response to numerous biotic and abiotic stresses [1]. In order to deal with these stresses, during the course of evolution, plants have developed multifaceted processes to recognize the stress stimuli, transfer them to the plant's own message(s) and complete the signal transduction pathways [2,3]. In response to the stresses due to pathogens, plants have developed race-specific and race non-specific resistance, known as qualitative and quantitative resistance, respectively [4]. Plants recruit proteins encoded by disease resistance (R) genes that recognize or interact with specific pathogen avirulence (avr) gene products [5] or effector molecules triggering a downstream signaling in resistance pathways [6,7]. Various models, such as Zig-zag and multicomponent models, propose a dynamic relationship between a host and its pathogen and explain how incompatible interactions between the hosts and pathogens lead to a selection of 
new $\mathrm{R}$ genes in response to co-evolutionary pressure due to pathogen races [6,8]. Host $\mathrm{R}$ genes can vary within a species, and their variation is correlated with that of the corresponding pathogen effectors [9]. For example, host polymorphic to $\mathrm{R}$ genes is found to provide partial resistance against pathogens [10]. Such partial resistance accumulates throughout the plant development and eventually provide quantitative resistance in the form of broad spectrum resistance [10]. Identification of $R$ genes and their pathogen effectors is essential for understanding host-pathogen interactions and disease resistance pathways in order to develop durable resistance in crop species.

The Pathogen Recognition Genes database (PRGdb, http://prgdb.org) listed $153 \mathrm{R}$ genes that have been cloned and characterized, and 177,072 annotated candidate Pathogen Receptor Genes (PRGs) [11]. These R genes encode mostly nucleotide binding site (NBS) leucine-rich repeat (LRR) proteins and have been classified into categories based upon the domains and motifs organization in the proteins [12,13]. Most commonly recognized categories are Toll-interleukin-1 receptor-like-NBS-LRR (TNL), Coiled-Coil-NBS-LRR (CNL), and Resistance to powdery mildew8 (RPW8)-NBS-LRR (RNL) [13,14]. All TNL, CNL and RNL genes are present in dicots, whereas TNL genes are absent in monocots [14,15]. Analysis of NBS genes in Fabaceae and Brassicaceae revealed that CNLs and RNLs diverged prior to divergence of Rosid I and Rosid II lineages of Angiosperms, and, in both plant families, the two clades are sister to each other [15,16]. The NBS domain, also known as NB-ARC where ARC stands for APAF1 (apoptotic protease-activating factor-1), R genes, and CED4 (Caenorhabditis elegans death-4 protein), hydrolyzes ATP to induce the conformational change in R proteins by acting as the nucleotide binding pocket [17]. The NBS domain mainly consists of P-loop, Kinase-2, RNBS A, GLPL and MHDL motifs [14]. The LRR domains at the C-terminus help activate or deactivate the defense signaling by interacting with the NBS domain in the presence or absence of pathogen effectors, respectively [18]. A diverse number of NBS genes have been reported in various plant species since the first study in Arabidopsis thaliana was published in 2003 [14]. With the increasing availability of plant genome sequences, $\mathrm{R}$ gene proteins have been identified in many plant species, such as A. thaliana [5,14]; Vaccinium spp. [19]; Amborella trichopoda, Musa acuminata, Phyllostachys heterocycla, Capsicum annuum, and Sesamum indicum by Shao et al. 2016 [13]; Cicer arietinum [20]; Glycine max [21-24]; Oryza sativa [25,26]; Medicago truncatula [27]; Vitis vinifera and Populus trichocarpa by Yang et al. 2008 [28]; Solanum tuberosum [29]; Brassica rapa and Brassica oleracea by Zhang et al. 2016 [30]; Hordeum vulgare [31]; Setaria italica [32]; Theobroma cacao [5]; Populus trichocarpa [5]; V. vinifera [5]; Cucumis sativus [33]; Phaseolus vulgaris [16,24], Lotus japonicas, Cajanus cajan, Glycine soja by Zheng et al. 2016 [16], Gossypium arboretum [34], etc. A recent study by Li et al. 2016 [35] has identified NBS-encoding genes as well as receptor-like protein kinases (RLKs) and receptor-like proteins (RLPs), collectively called as Resistance Gene Analogs (RGAs), for 50 plant genomes using a RGAugury pipeline.

According to a report by Food and Agriculture Organization (FAO) in 2010 (http: / / www.fao.org), domesticated Helianthus annuus L. (Family Asteraceae), is the fourth most important oilseed crop in the world. Since sunflower has the capacity to maintain sTable yields in different environmental conditions such as drought, it has been a model crop species for studying climate change adaptation [36]. The study on diversity analysis of 128 expressed sequenced tag (EST)-based microsatellites in wild $H$. annuus has provided insights into the ability to adapt salt and drought stress and selective sweeps revealing transcription factors as the major group of genes involved in those processes [36]. In addition, studies on wild and cultivated relatives of sunflower on disease resistance [37] and oil content [38] aspects have played great roles in understanding the genetic background for these traits. However, many fungal diseases like charcoal rot (Macrophomina phseolina), downy mildew (Plasmopara halstedii), Fusarium rot and stem rots (Fusarium sp.), phoma black stem (Phoma macdonaldii), phomopsis stem canker (Diaporthe helianthi, D. gulyae), Sclerotinia mid and basal stem rot (Sclerotinia scelerotiorum), Verticillium wilt (Verticillium dahlia), leaf blight (Alternariaster helianthi), leaf spot (Pseudomonas syringae pv. helianthi), powdery mildew (Erysiphe cichoracearum), rust (Puccinia helianthi) and many others have caused crop damage resulting in the loss of yield and oil content [39]. 
Previously, various studies have contributed their findings about the NBS group of R genes in sunflower [40-43]. Plocik et al. 2004 [40] identified nine sunflower resistance gene candidates with coiled-coil (CC) domains in the N-terminal region using degenerate primer sets. Sunflower showed diverse structures in CC subfamily, while lettuce and chicory, closely related species, showed high similarity in structure. Radwan et al. 2008 [42] used degenerate primers to identify 630 NBS-LRR homologs in wild species of sunflower (Helianthus annuus, Helianthus argophyllus, Helianthus deserticola, Helianthus paradoxus, and Helianthus tuberosus). In addition, Radwan et al. 2004 [43] isolated R gene analogs belonging to the CNL class of R genes from the inbred sunflower line QIR8 containing Pl8I locus against $P$. halstedii, which causes downy mildew. Later, Hewezi et al. 2006 [41] cloned partial antisense PLFOR48, which showed homology to the TNL family, in mildew resistant sunflower line, RHA 266 and Nicotiana tabacum L. The recent availability of the H. annuus genome [44] has now made it possible for studying the diversity and evolution of gene families in sunflower. The main objectives of this research were to conduct a genome-wide search for $H$. annuus NBS genes and analyze their genomic structure and functions. A proper identification of the $\mathrm{R}$ genes is crucial to elucidate their roles against various diseases in sunflower.

\section{Materials and Methods}

\subsection{Retrieval and Identification of Sunflower NBS-Encoding Genes}

The genome of sunflower (INRA inbred genotype XRQ described in [44]; H. annuus r1.2) was accessed from the sunflower genome database (https://www.sunflowergenome.org) as well as Phytozome (https:/ / phytozome.jgi.doe.gov). The sunflower genome is 3.6 gigabases and its genes distributed over 17 chromosomes encode 52,243 proteins (https:/ / phytozome.jgi.doe.gov). A. thaliana TNL and CNL (= nonTNL or nTNL) protein sequences were used as reference for the identification of NBS-LRR proteins in sunflower, and were obtained from http:/ / niblrrs.ucdavis.edu. The multiple sequence alignment file of these reference sequences in Stockholm format were employed in hmmbuild and hmmsearch for HMM profiling using the program HMMER version 3.1b2 [45] at a cut-off value of 0.01. InterProScan Version 5.27 (EMBL-European Bioinformatics Institute, UK) [46] and Pfam ID [47] and PROSITE ID (http:/ / prosite.expasy.org/) were used to search for the conserved domains. The proteins with PfamID of TIR (PF01582), NBS (PF00931), RPW8 (PF05659), CC and LRR domains with 'LxxLxxLxx' signatures were selected to determine the NBS proteins in sunflower. Further verification of the CC domains at the $\mathrm{N}$-terminus was carried out using the MARCOIL server [48] with a 9FAM matrix having probability between $0.4-1$. Multiple expectation maximization for motif elicitation (MEME) [49] analysis was performed to confirm the presence of P-loop, Kinase-2, GLPL, MHDL, RNBS A, RNBS B, RNBS C, and RNBS D motifs in the NBS domain, TIR1, TIR2, TIR3 motifs in TIR domain and RPW8 motifs in RPW8 domains. A set of parameters used in MEME analysis included maxsize: 100,000, mod: zoops, nmotifs: 20, minw: 6, and maxw: 50 to 25. Subcellular localization of the putative NBS genes were analyzed using TargetP 1.1 [50]. The program NLStradamus [51] was used to examine nuclear localization signals (NLS) in identified NBS genes of sunflower using a two-state HMM static model with Viterbi and posterior prediction methods (with 0.5 cut-off).

\subsection{Phylogenetic Tree Construction}

The NBS protein sequences from A. thaliana and H. annuus were aligned using CLUSTAL W [52] and MUSCLE [53] integrated in the program Geneious [54]. Phylogenetic analysis of the aligned data matrix was performed using Maximum Likelihood (ML) method (1000 replicates) in the program MEGA Version 7.0.14 [55]. The phylogenetic analysis employed the best evolutionary model (resulted from the ModelTest analysis using MEGA7) JTT $+\mathrm{G}+\mathrm{I}$ (Jones-Taylor-Thornton with $\gamma$ distribution and invariant sites), and Streptomyces coelicolor accession P25941 as an outgroup [14]. Additional phylogenetic trees of the NBS domains of predicted TNL and CNL proteins of sunflower and all reference proteins obtained from http://prgdb.crg.eu were reconstructed using the methods and 
models described above. Thus, the obtained Newick format of phylogenetic trees were employed in the Interactive tree of life (iTOL) Version 3 (Biobyte solutions GmbH, Bothestr, Germany) for their visual enhancement [56].

\subsection{Chromosomal Locations, Clustering and Gene Structure}

All 17 chromosome sequences of $H$. annuus were obtained from https:/ / www.sunflowergenome. org and uploaded in the program Geneious [54]. The chromosome locations of the respective gene families were visualized using an annotation file in Generic Feature Format (GFF). The NBS gene locations, NBS types and clustering were visualized on their respective chromosomes. Gene clustering of the NBS genes was carried out following Jupe et al. 2012 [57], using two major criteria: (a) distance between two NBS genes is less than $200 \mathrm{~kb}$, and (b) presence of no more than eight annotated non-NBS sequences between two consecutive NBS sequences. The exon-intron distribution pattern was obtained by the Gene Structure Display Server (http:/ / gsds.cbi.pku.edu.cn).

\section{4. $K_{a} / K_{s}$ and Syntenic Analysis}

Coding sequences (CDS) of the NBS genes were used in calculating nonsynonymous substitutions per nonsynonymous site $\left(K_{a}\right)$ and synonymous substitutions per synonymous site $\left(K_{s}\right)$ in the program DnaSP 6.11.01 [58]. Syntenic map of the NBS genes of H. annuus and A. thaliana was created using SyMAP Version 4.2 (Arizona Genomics Computational Lab, Tucson, AZ, USA) [59], executed within South Dakota State University's High-Performance Computing Cluster. Whole chromosome sequences and gene annotation files were used as input files for syntenic mapping of H. annuus and A. thaliana.

\subsection{Gene Homology and Expression Analysis}

Putative homologs of the predicted sunflower NBS genes were accessed using BLAST tool available in http:/ / prgdb.org with reference genes of PRGdb and a cutoff E-value of 0.01. The filtering included sequences with E-values less than 0.01 and identity percentage of greater than $50 \%$. Expression profiles of the putative NBS genes were downloaded from https:/ / www.sunflowergenome. org. A heatmap was generated using deseq normalized data through the MeV package, available at http://mev.tm4.org/ [60]. The heatmap clustering was performed based on Euclidean distance under 1000 iterations using the K-means Clustering Method. The clustering classification used these categories: moderate to minimal expression, minimal expression to no expression, and no expression at all.

\section{Results}

\subsection{Diversity of the NBS-Encoding Genes in Sunflower}

The HMM analysis of all sunflower protein-coding genes using the reference sequences of A. thaliana resulted in 485 NBS proteins, using a filtering threshold expectation value of 0.01 . These sequences were further annotated with InterProscan, and evaluated for the presence of NBS domains in each sequence. After a careful examination, 352 protein sequences were confirmed to have an NBS domain. Among these, 100 genes belonging to CNL group (after verification using MARCOIL server omitted ten false positives), 77 to TNL, 13 to RNL group, as well as 162 genes possess neither CC nor TIR domains thus classified as an NL group. Among 100 CNL types, 64 possesses a CC domain similar to $S$. tuberosum disease resistance protein $(\mathrm{Rx})$. Furthermore, Leucine-rich repeats (LxxLxxLxx signatures) were examined to classify CNLs, TNLs, RNLs and NLs into their subgroups. Following the classification of NBS-encoding genes in Brassica species and A. thatiana [5], the NBS genes were classified into: CC-NBS-LRR (CNL), CC-NBS (CN), CC-NBS-NBS-LRR (CNNL), CC-NBS-NBS (CNN), RPW8-NBS-LRR (RNL), RPW8-NBS (RN), RPW8-CC-LRR (RCL), TIR-NBS-LRR (TNL), TIR-NBS (TN), TIR-TIR-NBS-LRR (TTNL), TIR-NBS-LRR-TIR-NBS-LRR (TNLTNL), TIR-CC-NBS-LRR (CTNL), TIR-CC-NBS (CTN), NBS (N), NBS-LRR (NL), NBS-NBS (NN), and NBS-NBS-LRR (NNL) (see Table 1, 
Figures S1-S4). The LxxLxxLxx (=LRRs) signatures were present in 97 (out of 100) CNL genes with their LRRs ranging from two to 22, 12 (of 13) RNL genes with one to eight LRRs, 55 (of 77) TNL genes with two to 26 LRRs, and 131 (of 162) NL genes with two to 30 LRRs. Among them, HanXRQChr02g0052061, a TNL protein sequence contained a unique Kelch motif sequence (PF01344). TargetP analysis showed that 20 NBS proteins were predicted to localize to the chloroplast, 14 to mitochondria, 80 enter the secretory pathway, and 238 were predicted to enter other subcellular locations other than mitochondria or the chloroplast (Table S1). Thirteen CNLs, seven TNLs, one RNL, and eight NLs were identified to contain a putative NLS using NLStradamus (Table S2).

Three major signature motifs: P-loop, Kinase-2, and GLPL of the NBS domain of disease resistance proteins were present in 57 out of 100 CNLs, 69 out of 77 TNLs, all 13 RNLs and 58 out of 162 NLs (Supplementary File S1, Figures S5-S7). Other important motifs RNBS A, RNBS B, RNBS C and RNBS $\mathrm{D}$, and MHDL were also present in the NBS proteins (Tables S3-S5). Motifs TIR1, TIR2, TIR3, and TIR4 varied in number across the TNL genes: among the 77 TNLs, 76 had TIR1, 76 had TIR2, 75 had TIR3 and 76 had TIR4 motifs. Only two TNLs (HanXRQChr05g0136351 and HanXRQChr06g0184071) did not have all four TIR motifs. Of the $100 \mathrm{CNLs}, 81$ had the characteristic conserved amino acid sequence 'DDVW' in the Kinase-2 motif. Remaining CNLs had either Isoleucine (I), Methionine (M), or Leucine (L) in the place of Valine (V) amino acid in the sequence 'DDVW'. Of the 77 TNLs, 50 shared the characteristic 'DDVD' amino acid sequence in the Kinase-2 motif. Of the 162 NLs, 83 had 'DDVW' and

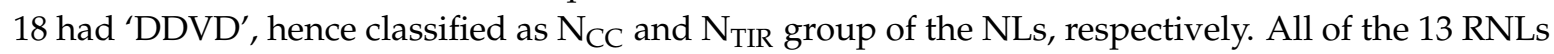
had 'DDVW' sequence in the Kinase-2 motif except for HanXRQChr03g0067681 with 'DDVR' sequence. Another key characteristic found within the RNBS B motif was that the majority of the CNLs had 'TSR', TNLs had 'TTRD', and RNLs had 'TSR' residues. The sequence alignments illustrating all the conserved motifs of the CNLs, TNLs, and RNLs are presented in Supplementary File S2.

\subsection{Gene Location, Clustering, $K_{a} / K_{s}$ Values and Structural Variation}

The NBS genes are located on each of the chromosomes, with only four (HanXRQChr00c0003g0570971, HanXRQChr00c0003g0570951, HanXRQChr00c0004g0571011, and HanXRQChr00c0037g0571241) were not assigned to any chromosome (Figure S8). The number of the NBS genes located on each chromosome ranged from three (chromosome Ha12) to 99 (chromosome Ha13). Chromosomal distribution of the CNL, TNL, RNL, and NL genes and their clusters are shown in Figure 1. The CNL genes were absent in chromosomes Ha3, Ha5, and Ha16, whereas, TNL genes were absent in chromosomes Ha7 and Ha11. Most of the TNL genes were uniformly distributed across the chromosomes, whereas most of the CNL and NL genes were densely represented on chromosome Ha13 (approximately 28\%). The smallest number of RNL genes (thirteen) were present in chromosomes Ha2, Ha3, Ha4, Ha5, Ha7, Ha11, Ha14, and Ha15 (see Figure 1). Among the 352 NBS genes, 200 ( $57 \%)$ genes formed 75 clusters (4.4 clusters per chromosome and 2.7 genes per cluster) with chromosome Ha13 hosting 25 clusters of 73 genes ( 37\%; Table S6). The gene clusters were present in all chromosomes except for Ha5 and Ha12. Gene positions and clusters on chromosomes of $H$. annuus are shown in Figure 2 . The average $K_{a} / K_{s}$ values for the clades of CNLs, TNLs, and RNLs were $0.68,0.89$, and 0.31 , respectively. The number of exons in the genes is shown in Table S1 and Figures S9-S12. The number of exons for CNLs, TNLs, RNLs, and NLs ranged from 1 to 11,2 to 18,4 to 9 , and 1 to 19, respectively. In average CNLs, TNLs, RNLs, and NLs had $2.7,6.1,6.2$, and 2.9 exons per gene, respectively. 
Table 1. Nucleotide Binding Site (NBS)-encoding proteins in sunflower in relation to 15 other plant species.

\begin{tabular}{|c|c|c|c|c|c|c|c|c|c|c|c|c|c|c|c|c|}
\hline \multirow[t]{2}{*}{ Protein Letter Code } & \multicolumn{16}{|c|}{ Number of Proteins } \\
\hline & $\mathrm{Ha}^{*}$ & At $^{a}$ & $\mathrm{Gm}^{\mathrm{b}, \mathrm{c}}$ & $\mathrm{Mt}^{\mathrm{a}}$ & Bo $^{a}$ & $\mathrm{Br}^{\mathrm{a}}$ & $\mathrm{Tc}^{\mathrm{a}}$ & $\mathbf{P t}^{\mathrm{a}}$ & $\mathrm{Vv}^{\mathrm{a}}$ & $\mathrm{Ca}^{\mathrm{d}}$ & $\mathrm{Cs}^{\mathrm{e}}$ & $\operatorname{Pv}^{\mathrm{f}, \mathrm{c}}$ & $\mathrm{Lj}^{\mathrm{f}}$ & $\mathrm{Cc}^{\mathrm{f}}$ & $G s^{f}$ & $\mathrm{Ga}^{\mathrm{g}}$ \\
\hline CNL & 90 & 17 & 95 & 152 & 6 & 19 & 82 & 120 & 203 & 19 & 17 & 31 & 11 & 37 & 47 & 80 \\
\hline $\mathrm{CN}$ & 5 & 8 & - & 25 & 5 & 15 & 46 & 14 & 26 & 33 & 1 & 40 & 26 & 41 & 62 & 44 \\
\hline CNNL & 4 & - & 5 & - & - & 2 & - & - & - & 1 & - & - & - & - & - & - \\
\hline CNN & 1 & - & - & - & - & - & - & - & - & - & - & - & - & - & - & - \\
\hline RNL & 10 & 2 & 6 & - & 1 & 4 & - & - & - & 2 & 2 & - & - & - & - & 3 \\
\hline $\mathrm{RN}$ & 1 & 3 & - & - & 2 & 1 & - & - & - & 2 & - & - & - & - & - & - \\
\hline $\mathrm{RCNL}$ & 2 & - & - & - & - & - & - & - & - & - & - & - & - & - & - & - \\
\hline TNL & 52 & 79 & 126 & 118 & 40 & 93 & 8 & 78 & 97 & 6 & 11 & 81 & 16 & 47 & 49 & 5 \\
\hline $\mathrm{TN}$ & 21 & 17 & 22 & 38 & 29 & 23 & 4 & 10 & 14 & 7 & 2 & 11 & 53 & 36 & 76 & 2 \\
\hline TNNL & 0 & 1 & - & - & 1 & 4 & - & - & - & - & - & - & - & - & - & - \\
\hline TTNL & 1 & - & - & - & - & - & - & - & - & 1 & - & - & - & - & - & - \\
\hline TNLTNL & 1 & - & - & - & - & - & - & - & - & - & - & - & - & - & - & - \\
\hline CTNL & 1 & - & - & - & - & - & - & - & - & - & - & - & - & - & - & - \\
\hline CTN & 1 & - & - & - & - & - & - & - & - & - & - & - & - & - & - & - \\
\hline $\mathrm{N}$ & 29 & 26 & 4 & 328 & 53 & 29 & 53 & 62 & 36 & 14 & 1 & 59 & 82 & 136 & 213 & 59 \\
\hline NL & 125 & 20 & 73 & - & 24 & 27 & 104 & 132 & 159 & 12 & 23 & 20 & 18 & 56 & 58 & 53 \\
\hline $\mathrm{NN}$ & 2 & - & - & - & 3 & 2 & - & - & - & 1 & - & - & - & - & - & - \\
\hline NNL & 6 & - & - & - & - & 3 & - & - & - & - & - & - & - & - & - & - \\
\hline
\end{tabular}

Note: Ha: Helianthus annuus; At: Arabidopsis thaliana; Gm: Glycine max; Mt: Medicago truncatula; Bo: Brassica oleracea; Br: Brassica rapa; Tc: Theobroma cacao; Pt: Populus trichocarpa; Vv: Vitis vinifera; Ca: Cicer arietinum; Cs: Cucumus sativus; Pv: Phaseolus vulgaris; Lj: Lotus japonicas; Cc: Cajanus cajan; Gs: Glycine soja; Ga: Gossypium arboretum $\left({ }^{*}=\right.$ this study, ${ }^{\mathrm{a}}=[5],{ }^{\mathrm{b}}=[23],{ }^{\mathrm{c}}=[24]$, $\left.\mathrm{d}=[20],{ }^{\mathrm{e}}=[33],{ }^{\mathrm{f}}=[16], \mathrm{g}=[34]\right)$. 
Figure 1. Chromosomal distribution (Ha1-Ha17) of the NBS genes and gene clusters in sunflower. Different NBS groups and gene clusters are color coded. CNL: Coiled-Coil-NBS-LRR; TNL: Tollinterleukin-1 receptor-like-NBS-LRR, RNL: Resistance to powdery mildew8 (RPW8)-NBS-LRR; NL: Nucleotide Binding Site-Leucine-Rich Repeat (NBS-LRR).

\subsection{Phylogenetic and Syntenic Analysis}

The data matrix with the NBS aligned sequences (NBS domain region is more conserved than remaining $5^{\prime}$ and $3^{\prime}$ regions) was used in phylogenetic analyses. Phylogenetic relationships among the sunflower NBS sequences are shown in Figure 3, and those of the sunflower and Arabidopsis NBS sequences are shown in Figure 4; each tree reveals distinct clades of CNLs, RNLs and TNLs. The RNL clade was surprisingly nested within the TNL clade. As shown in Figure 3, the CNLs and TNLs formed six subclades each. The TNL subclades are named TIR (I), TIR (II), TIR (III), TIR (IV), TIR (V), and TIR (VI), whereas CNL subclades are named CC (I), CC (II), CC (III), CC (IV), CC (V), and CC (VI). The phylogenetic tree reconstructed using sunflower and Arabidopsis NBS sequences revealed clade-specific nesting patterns in the CNL group (Figure 4). The nesting of all sunflower RNL genes within CNL-A clade (with Arabidopsis RPW8 genes) was strongly supported (bootstrap support $=96 \%$ ). CNL-C (I) clade constituted six CNL genes (HanXQRChr14g0440091, HanXQRChr17g0562451, HanXQRChr12g0374601, HanXQRChr08g0224171, HanXQRChr13g0417971, and HanXQRChr13g0417981) with a weak support [bootstrap support (BS) $=57 \%$ ]. CNL-C (I) clade, sister clade to CNL-C (II) and CNL-D constituted 79 genes. CNL-B clade constituted three genes (HanXQRChr02g0046161, HanXQRChr11g0333001, and HanXQRChr11g0333091). The remaining 12 genes did not belong to any clade of Arabidopsis CNL genes. The TNL group formed a species-specific clade, except ten genes that formed a small clade with AT5G36930, named TNL-D clade with strong bootstrap support of $100 \%$. We found a moderate bootstrap support (BS $=50 \%$ ) for CNL-A clade being nested within TNL clade making both the CNL and TNL clades paraphyletic. Another tree constructed using RNL genes of $A$. thaliana and $H$. annuus showed two distinct clades for two lineages: activated disease resistance gene 1 (ADR1) and N-required gene 1 (NRG1) (Figure 5). The Newick files related to phylogenetic trees in Figures 3-5 are provided in Supplementary File S3. For the comparative study, all the manually curated TNL and CNL reference proteins obtained from http:/ / prgdb.crg.eu were phylogenetically compared with sunflower TNL and CNL NBS proteins. The sunflower NBS 
proteins formed clades with various reference proteins such as Pi36, P18, Rps2, VAT, RPG1, Gro1.4, RY-1, and N proteins suggesting their homologs (Figure S13). The syntenic relationship between the Arabidopsis's 119,146 kb genome and sunflower's 3,641,596 kb genome showed 87 syntenic blocks with 1049 synteny hits. The chromosome 2 of Arabidopsis was highly syntenic to chromosome Ha1, Ha2, Ha3, and Ha15 chromosomes of sunflower. Similarly, the highest syntenic region was observed between chromosomes 5 of Arabidopsis and chromosome 6 of sunflower. The sunflower chromosomes Ha2, Ha5, Ha11, Ha13, Ha15, and Ha17 are least syntenic to any of the chromosome of Arabidopsis. The pericentromeric region of the sunflower chromosomes Ha3, Ha9, and Ha14 were highly syntenic to the chromosomes of Arabidopsis. The chromosome Ha13 that contains 99 NBS genes contains fragments from only chromosome 2 of Arabidopsis (Figure S14).

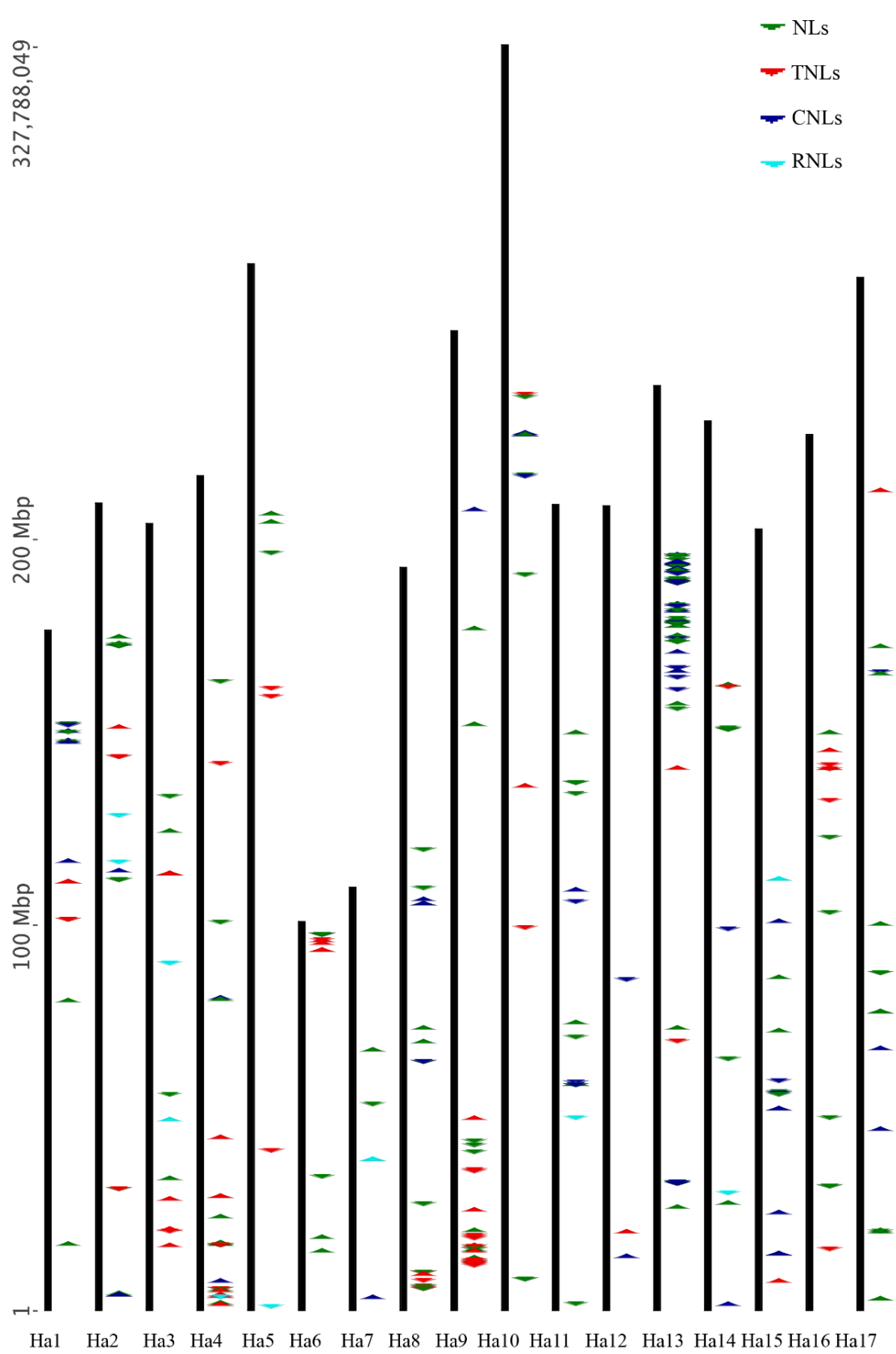

Figure 2. Chromosomal distribution of sunflower NBS gene clusters $(n=17)$. Each arrow color represents an NBS gene type and orientation, and the thick vertical line represents a chromosome. 


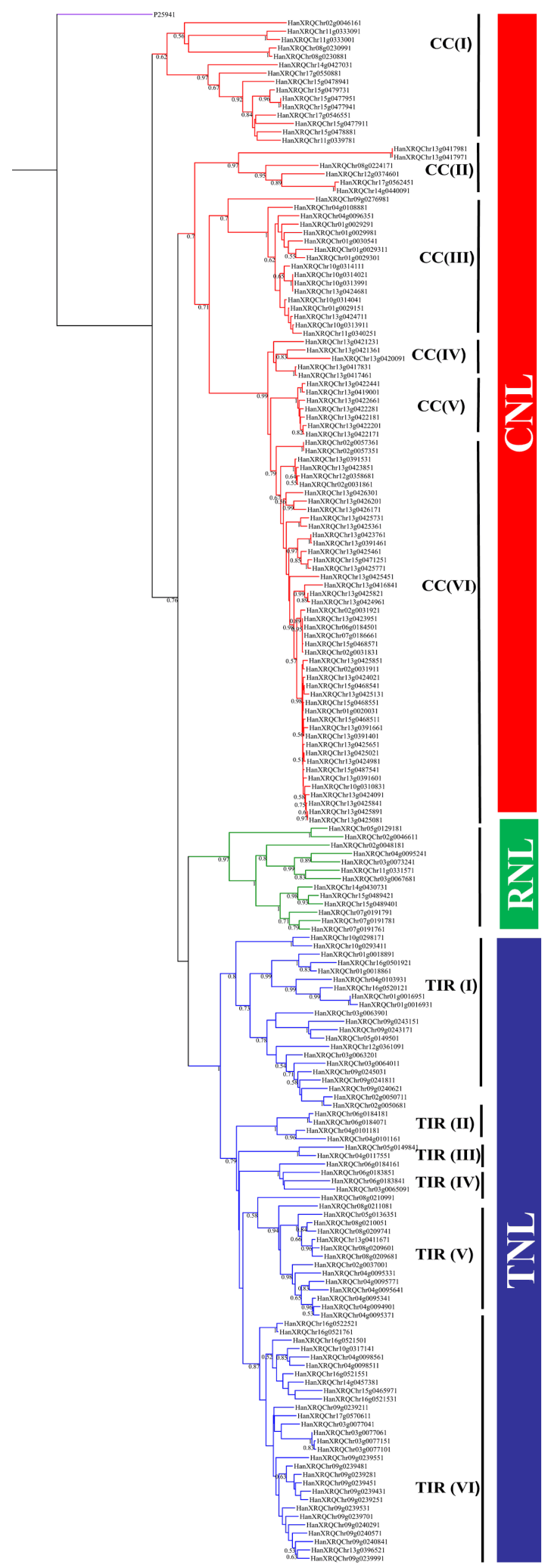

Figure 3. Maximum likelihood (ML) tree featuring NBS groups based on the conserved domains of the $\mathrm{CNL}, \mathrm{TNL}$, and RNL genes from Helianthus annuus. The ML tree was constructed using the JTT + G + I (Jones-Taylor-Thornton with $\gamma$ distribution and invariant sites) model with 1000 bootstrap replicates. The ML tree was rooted using a Streptomyces coelicolor NBS containing protein, P25941, as an outgroup. The clades TNL (blue), CNL (red), and RNL (green) and outgroup (purple) are color-coded. Subclades are mentioned as TIR (I) to TIR (VI) and CC (I) to CC (VI). 


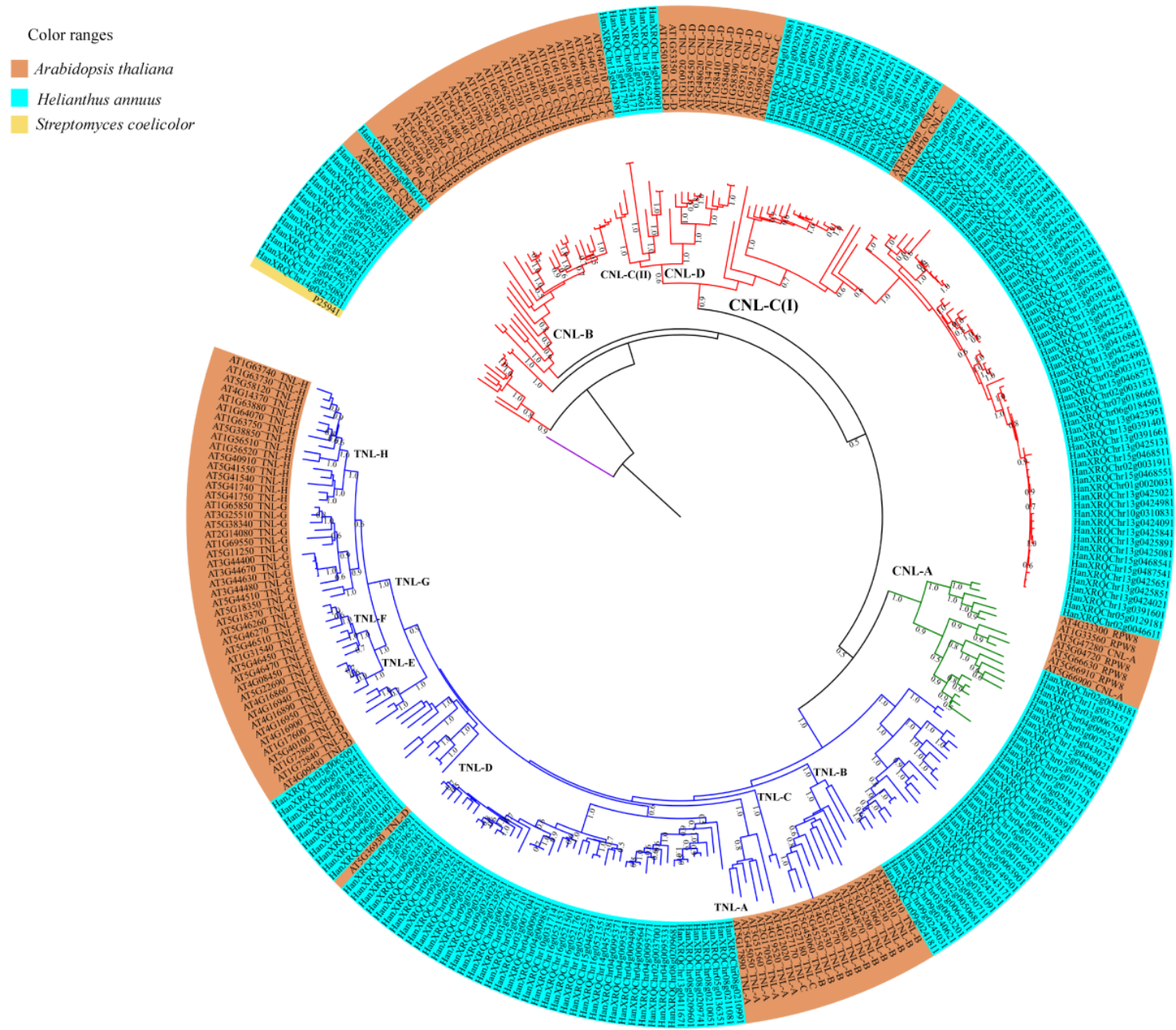

Figure 4. Maximum likelihood (ML) tree featuring NBS domain amino acid sequences of the CNL, TNL, and RNL genes from Arabidopsis thaliana (AT; orange) and Helianthus annuus (light blue). The ML tree was reconstructed using JTT $+\mathrm{G}+\mathrm{I}$ (Jones-Taylor-Thornton with $\gamma$ distribution and invariant sites) evolutionary model with 1000 bootstrap replicates. The ML tree was rooted using Streptomyces coelicolor NBS-containing protein, P25941, as an outgroup (yellow). The clades are color-coded: TNL in blue, CNL in red, RNL clade in green, and outgroup in purple. Subclades are labeled as CNL-A to CNL-D and TNL-A to TNL-H.

\subsection{Homologs and Expression Analysis}

The predicted 352 NBS proteins of sunflower showed homology, with identity greater than $50 \%$ and E-value less than 0.01, to 39 genes among 153 reference genes on the Plant Resistance Genes database (Table S7). Among them, 21 proteins showed greater than $70 \%$ identity to the H. annuus clone Ha-NTIR11g CC-NBS-LRR gene (Pl8). HanXRQChr13g0425411, HanXRQChr13g0425361, and HanXRQChr13g0425431 showed more than an $80 \%$ identity to the Pl8 gene suggesting the probable homologs to that gene. HanXRQChr04g0123041, belonging to the NL group has shown homology to Lycopersicon esculentum EIX receptor 1 (LeEIX1), a gene that encodes receptor-like proteins (RLPs). Similarly, HanXRQChr17g0552491 showed homology to MLA10, HanXRQChr13g0420141 to N, HanXRQChr17g0552491 to both MLA12 and MLA13 and HanXRQChr17g0552491 to Sr33 protein with greater than $60 \%$ identity. Sunflower Genome Database with H. annuus $\mathrm{r} 1$ annotations was employed to obtain expression data for predicted NBS genes. We compared accessions of H. annuus r1.2 annotations to $H$. annuus $\mathrm{r} 1$ to obtain the expression data for NBS proteins. Since there were many duplicates for H. annuus r1.2 annotations, we used only the sequences with the unique names. 
The raw Read Per Kilobase Million) (RPKM) values of gene expression were downloaded separately. The expression values were from bract, corolla, leaves, ligule, ovary, pollen, seed, stamen and stem. Only expression data for 9 CNL type, 33 TNL type, 23 NL type and 6 RNL type genes were retrieved from the database and employed to generate heatmap after deseq normalization of the data using $\mathrm{MeV}$ package (Figure 6). Cluster I consists of 13 genes representing moderate to minimal expression, cluster II with 43 genes representing basal to no expression and cluster III with 15 genes representing minimal expression to basal expression (Figure S15).

Tree scale: $0.1 \longmapsto$

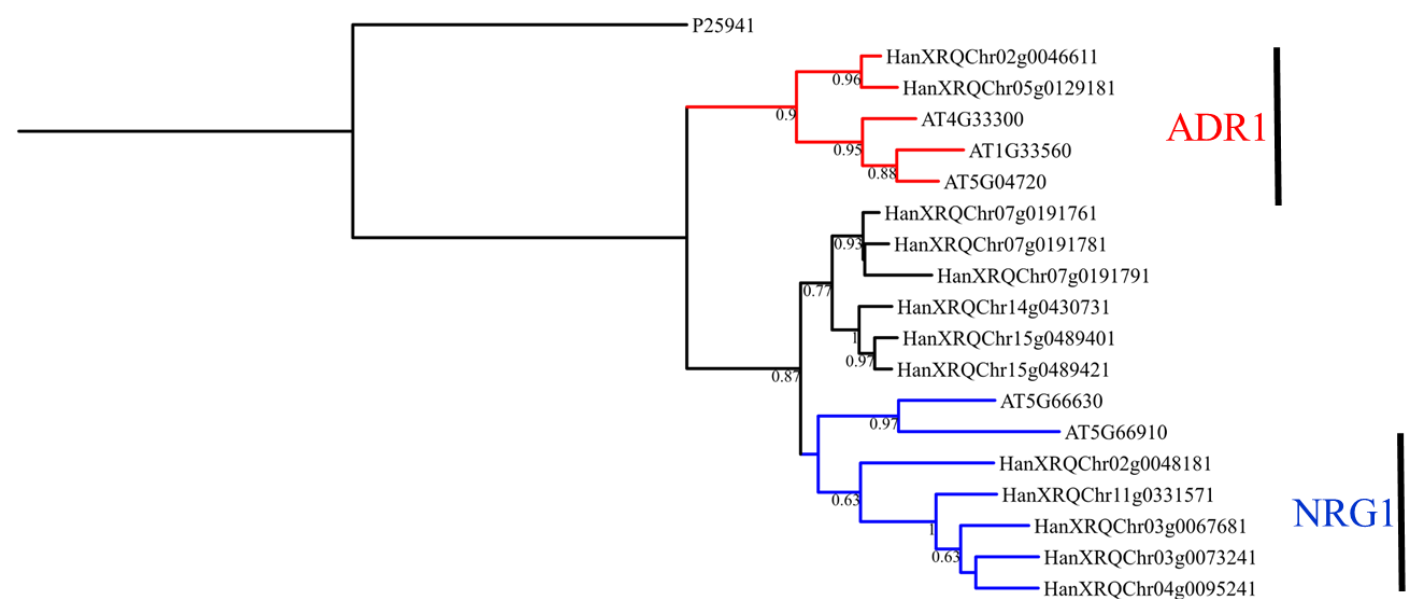

Figure 5. Phylogenetic relationships of RNL proteins in Arabidopsis thaliana and Helianthus annuus. The clades N-required gene 1 (NRG1) and activated disease resistance gene 1 (ADR1) are color-coded in blue and red, respectively. The tree was rooted using Streptomyces coelicolor NBS-containing protein, P25941, as an outgroup.

\section{Discussion}

\subsection{Diversity of NBS-Encoding Genes}

Our findings on the NBS-encoding genes in this study is based on recently sequenced sunflower genome [44]. Previously, Gedil et al. 2001 [61] identified RGC fragments with the NBS domains and assigned to 11 groups among which Ha4W2A was linked to Pl1, a downy mildew resistance gene. Plocik et al. 2004 [40] identified nine unique NBS domain sequences using degenerate primers in sunflower and compared them to lettuce, chicory and A. thaliana. They concluded that NBS gene sequences of Asteraceae family are ancestral to the Brassicaceae family. Later, Radwan et al. 2008 [42] identified 118 and 95 NBS domain sequences in RHA373 and ANN-1811 germplasm of H. annuus, respectively. In this study, we identified 352 NBS-encoding genes that constitute $0.67 \%$ of the total predicted proteins in sunflower, which shows similarity to M. truncatula $(\sim 0.66 \%)$ [27]. This number is higher than that of Arabidopsis ( 0.43\%) [14], C. sativus ( 0.21\%) [33], Carica papaya $(\sim 0.21 \%)$ [62] and lower than that of P. vulgaris ( 1.19\%) [63], Manihot esculenta ( 0.9\%) [64], V. vinifera ( 1.3\%) [28], and G. $\max (\sim 0.73 \%)[23,24]$. We performed protein blast (BLASTp) analyses using 352 NBS domains of NBS-encoding genes identified in this study against a database with previously studied NBS domain sequences. The BLASTp analyses against a database comprised of sequences from Gedil et al. 2001 [61], Plocik et al. 2004 [40], and Radwan et al. 2008 [42] showed 70 to 100\% identity to 143, 68 and 100 NBS domain sequences identified in this study, respectively (Supplementary File S4). 


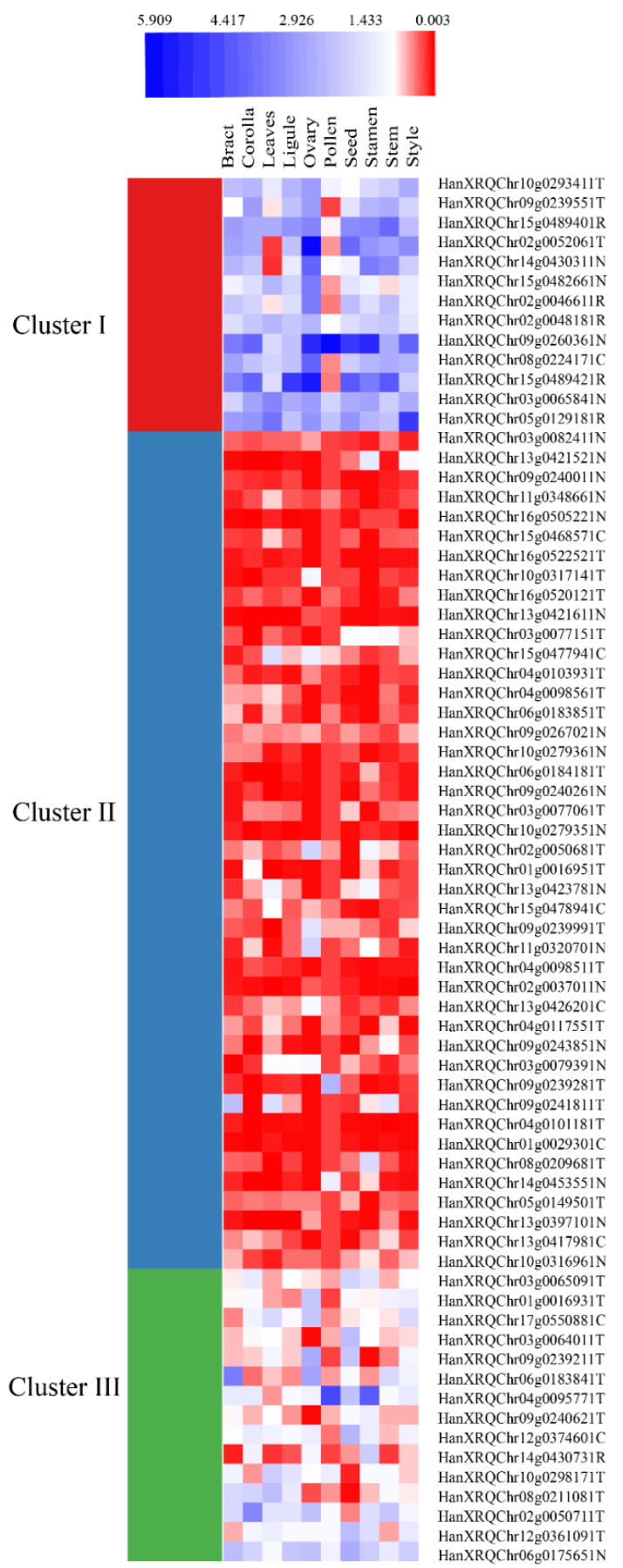

Figure 6. Expression profile of NBS genes from sunflower visualized as heatmap. The heatmap was generated using deseq normalized data for sunflower NBS genes expression in different tissues. K-means Clustering Method was employed for clustering (I, II and III). Gene IDs are followed by NBS type (C: CNLs; T: TNLs; N: NLs and R: RNLs).

Following the classification of NBS genes by Shao et al. 2016 [13] and Yu et al. 2014 [5], we classified NBS genes of sunflower into CNL, TNL, RNL and NL groups and their subgroups. We identified 100 genes belonging to the CNL group, with 64 possessing RX_CC like domain, 77 to the TNL group, 13 to the RNL group, and 162 to the NL group. In sunflower, the number of CNLs was found to be higher than that of TNLs, and the ratio of CNLs to TNLs was 1.3:1. The CNL:TNL ratio in the current study is not consistent with the findings observed in some other dicot species such as $A$. thaliana (1:2), A. lyrata (1:2), B. rapa (1:2), Eucalyptus grandis (1:1.25), and Thellungiella salsuginea (1:1.5) as numbers of 
TNLs were higher than CNLs in these species [14,30,65-67]. However, grapevine, chickpea, and potato genomes constituted CNL:TNL in a ratio of 4:1 [20,28,57]. The higher number of CNLs in sunflower might suggest the higher contribution of these genes providing resistance against pest or pathogen attack, which warrants future investigation. Furthermore, these groups are classified into subgroups as CNLs were classified into four subgroups [CNL (90), CN (5), CNN (1), CNNL (4)], TNLs into six subgroups [TNL (52), TN (21), TTNL (1), TNLTNL (1), CTNL (1), CTN (1)], RNLs into three subgroups [RNL (10), RN (1), RCNL (2)], and NLs into four subgroups [N (29), NL (125), NN (2), NNL (6)]. The classification is based on the presence of the CC domain named as ' $C$ ', the presence of TIR domain as ' $\mathrm{T}$ ', the presence of RPW8 domain as ' $\mathrm{R}$ ', the presence of the NBS domain as ' $\mathrm{N}$ ', the presence of two NBS domains as ' $N N^{\prime}$ ', and the presence of LxxLxxLxx signatures as ' $\mathrm{L}$ ' in the amino acid sequences of the proteins. The CNL type constituted approximately $92 \%$ of the genes belonging to CNL subgroup, $67 \%$ of the genes belonging to TNL subgroup in the TNL type, $76 \%$ of the genes belonging to RNL subgroup in RNL type and 77\% of the NL types genes are comprised of NL subgroup genes. The subgroups CN, CNNL, N, NN, and TTNL were also observed in M. truncatula, A. thaliana, and B. rapa $[5,19,27]$. HanXRQChr03g0067681 and HanXRQChr03g0073241 constituted both RPW8 and coiled-coil domains in the N-terminal and named RCNL, which were also reported in A. thaliana and B. rapa [5]. HanXRQChr05g0136351 and HanXRQChr06g0184071 possessed both TIR and coiled coil domain in the N-terminal of NBS proteins of sunflower and named CTN and CTNL, respectively. Such subgroups have been previously reported in many legumes and blueberries [16,19].

NBS-encoding genes also called NBS-LRR genes encode proteins having TIR/CC at the N-terminal, NBS domain in the center and LRR at the C-terminal [14]. Among the identified NBS groups, genes belonging to NLs possessed less conserved NBS domain, as only $32 \%$ of the genes possessed all three signature motifs, while $57 \%$ of the CNLs, $89 \%$ of TNLs, and $100 \%$ of RNLs possessed all three signature motifs. Of the $100 \mathrm{CNLs}, 64$ genes possessed Rx_CC like domain in their N-terminal region. The disease resistance protein Rx possess $\mathrm{CC}$ domain in the $\mathrm{N}$-terminal, and is expressed against potato virus $X$ in S. tuberosum [68]. All TIR1, TIR2, TIR3 and TIR4 were detected in the TNLs of sunflower, which shows the consistency of TIR domain as described in other plant species such as A. thaliana, P. vulgaris, G. max, and P. trichocarpa $[14,24,63,69]$. The characteristic 'DDVW' sequence was conserved in kinase-2 motifs of RNL and CNL genes, whereas 'DDVD' sequence was frequently found in TNL genes. The 'TSR' sequence was highly conserved in RNBS B motifs of the RNLs, while it slightly varies as 'TTR' and 'TTRD' in the CNLs and TNLs, respectively. This was found to be consistent with the large scale study of NBS proteins in angiosperms [13]. All of the identified NBS proteins possessed MHDL motifs, except for the RNL genes, frequently possessing QHDL motif. Such QHDL motifs were observed in NBS proteins of P. trichocarpa [69]. A unique Kelch motif sequence was observed in HanXRQChr02g0052061 protein. Previously, Kelch motifs were reported in the NBS proteins of B. rapa [5]. Kelch motif sequences are considered to be signature motif for positive selection mostly found at the C-terminal of F-Box proteins and are well studied in plant species such as A. thaliana, P. trichocarpa, and O. sativa [70].

We further compared our pipeline with another pipeline, RGAugury [35], for the identification of NBS-encoding genes. RGAugury is the integrative pipeline that facilitates the prediction of NBS-encoding genes, RLKs, and RLPs [35]. RGAugury predicted all 352 NBS proteins identified in this study plus five more proteins [HanXRQChr02g0037021 (TN), HanXRQChr09g0240471 (TN), HanXRQChr11g0340171 (CNL), HanXRQChr13g0394521 (TN), and HanXRQChr16g0515381 (CN)] and 25 belonging TX (absence of NBS domain) subclass. These missed proteins were manually checked and NBS domain (PF00931) in HanXRQChr09g0240471, HanXRQChr11g0340171, HanXRQChr13g0394521, and HanXRQChr16g0515381 were absent except in HanXRQChr02g0037021 (could belong to TN subgroup). In addition, we suggest HanXRQChr09g0240471 to be classified as a TX subclass. We found some discrepancies in the CNL group counts between two pipelines. The use of a MARCOIL tool in our pipeline helped with filtering false positives from the CNL group counts, and we could not observe any discrepancies in the TNL group counts between the two pipelines. Furthermore, the RGAugury 
pipeline could not identify an RNL group of genes that were identified in this study and majorly categorized them to NL group ( $\mathrm{N}$ and NL subclasses) of genes. The study and identification of TX proteins were beyond the scope of our study as these proteins were filtered out because of the absence of NBS domains. The differences and discrepancies between identification and classification of predicted NBS-encoding genes using our and RGAugury pipelines are represented in Supplementary File S5. In addition, RGAugury was employed to predict proteins belonging to RLP, RLK and Transmembrane-coiled-coil (TM-CC) proteins. A total of 257 RLPs [255-LRR type, 2-lysin motif (LysM) type], 1086 RLKs (368-LRR type, 12-LysM type and 706 Other-receptor type) and 173 TM-CC proteins were predicted in the sunflower (Supplementary File S5). Both RLKs and RLPs play important role in plant development and defense mechanism $[4,71]$. RLKs such as FLAGELLIN SENSITIVE 2 (FLS2) [72], elongation factor Tu receptor (EFR) [73], systemin cell-surface receptor (SR160) [74], Xa21 [75], ERECTA RLK [76] and many more are well characterized that are mainly involved in detection of pathogen associated molecular patterns (PAMPs). On the other hand, RLP (lacking Kinase-2 domain) such as Arabidopsis CLAVATA2 (CLV2, AtRLP10) [77] is involved in the development of meristem and $\mathrm{Cf}$ is involved in pathogenesis against Cladosporium fulvum in tomato [78].

\subsection{Gene Location, Clustering, $K_{a} / K_{s}$ Values and Structural Variation}

A variety of clustering patterns of NBS-encoding genes, frequently observed in almost all plant species, is one of the major reasons for rapid evolution of the NBS genes $[14,79]$. The NBS genes of sunflower formed 75 clusters, 25 of which reside in chromosome Ha13, 73 out of 200 ( 37\%) genes. In M. esculenta, 143 NBS genes positioned in 39 clusters [64]. In C. sativus, 33 NBS genes were located in nine clusters [33]. The average number of NBS proteins per cluster in sunflower was approximately 2.7, lesser than ratios in Solanaceae species such as tomato (3.48), potato (4.65), pepper (3.44) [80], Brassicaceae species such as B. oleracea (3.04), B. rapa (2.7), A. thaliana (2.8) [5], Fabaceae species such as G. max (4), V. vinifera (6), M. truncatula (5) [16], Gossypium species such as G. arboretum (3.4), G. raimondii (5.5), G. hirsutum (5.3), and G. barbadense (3.5) [34]. Both segmental and tandem duplications are responsible for the formation of new clusters that generate intraspecific variation by processes such as unequal crossing over $[9,14,81]$. However, NBS-encoding genes do not undergo high rates of mutation and maintain both intra- and inter-specific variation [9]. The average exon counts of sunflower CNLs (2.7 exons per gene) and TNLs (6.1 exons per gene) were consistent with CNLs (2.7 exons per gene) and TNLs (5.1) of Arabidopsis [14]. This implies a high number of exons of TNLs and RNLs could help with generating diverse resistance proteins through alternative splicing. All NBS types showed $K_{a} / K_{s}$ values of less than one, indicating that these genes are under the influence of purifying selection.

\subsection{Phylogenetic Relationships, Homology, Synteny and Expression Analysis}

Sunflower CNL genes were similar to $C$. sativus $C N L$ genes while compared to their respective TNL genes [33]. However, the CNL clade size in sunflower is different from Arabidopsis, as TNL clades constitute larger numbers of genes than CNL clade [14]. Subclades CC (I) possessed gene members with introns in range of one to ten, and CC (II) constituted gene members with introns in the range of zero to one. Other subclades, CC (III) and CC (IV) constituted gene members with introns in the range of zero to two and $\mathrm{CC}(\mathrm{V})$ and $\mathrm{CC}(\mathrm{VI})$ constituted gene members with introns in the range of zero to four. Only HanXRQChr02g0057361, HanXRQChr02g0057351, and HanXRQChr13g0425771 in the subclade CC (VI) possessed in the range of five to seven. Similarly, subclade TIR (II) possessed gene members with introns in the lowest range (three to five). TIR (I), TIR (III), TIR (IV), TIR (V) and TIR (VI) gene members possessed introns in range of 3 to 17,2 to 7,1 to six, 1 to 15 , and 1 to 13 , respectively. Similar patterns were also observed in the phylogenetic tree of CNL and TNL in C. sativus [33]. The differences in the clade pattern with correlation to introns in two gene families suggest the role of intron loss and gain in the structural evolution of the NBS genes as suggested by Wan et al. 2013 [33]. In addition, the position, presence or absence, and phase of introns often play important roles in phylogeny [82]. 
We found that RNLs were nested within the clade of TNLs in sunflower (a member of the Asterids lineage) although RNLs in the families Brassicaceae and Fabaceae (Rosids lineage) were found to be related to CNLs [15,30]. The lineage of Asterids is believed to have evolved from the rest of Angiosperms (Rosids + monocots + basal Angiosperms) little over 100 million years ago (MYA) [83]. A large-scale study of Angiosperms NBS genes also concluded that RNLs were sister to the CNLs [13]. However, these earlier studies did not include $H$. annuus in the analysis as the genome was not available by then. Our results indicate a surprising position of RNLs within TNLs in sunflower making the clades of TNL and CNL potentially paraphyletic. Upon reconstruction of the phylogenetic tree with Arabidopsis NBS genes, RNL genes of sunflower were observed in a CNL-A clade (although it is consistent with the previous study) [14]. The CNL-A clade did not consist of any sunflower CNL gene members besides RNLs. Further study on comparative genomics or transcriptomes across the Asterids lineage can confirm whether CNL genes are completely absent in the lineage. Shao et al. 2016 [13] suggested that RNLs were derived from ADR1 and NRG1, and two ancient lineages separated before the Angiosperms diversified. The RNL genes, ADR1 and NRG1, have been characterized in Arabidopsis and Nicotiana, respectively. A separate tree, constructed to observe the relationships among sunflower RNLs and Arabidopsis RNLs, formed two clades. The sunflower RNL genes HanXRQChr02g0046611 and HanXRQChr05g0129181 were nested with AT4G3330 (ADR1-L1), AT1G33560 (ADR1) and AT5G04720 (ADR1-L2 or PHX21), with bootstrap support of 90\%. On the other hand, HanXRQChr02g0048181, HanXRQChr11g0331571, HanXRQChr03g0067681, HanXRQChr0073241, and HanXRQChr04g0095241 were nested with AT5G66630 (RNL) and AT5G66910 (homologous to NRG1), with bootstrap support of $63 \%$. This suggests that the sunflower RNLs mentioned above are orthologous to the ADR1 and NRG1 homologs of Arabidopsis. ADR1 proteins play a role as helper genes for receiving signals from the R genes in downstream signaling of effector-triggered immunity [84]. Similarly, NRG1 proteins help the $\mathrm{N}$ protein during the pathogenesis by the tobacco mosaic virus [85]. Since they are not directly involved in detecting the pathogen effectors, they are not much influenced by a selection pressure due to the pathogens [13]. Only 5.8\% of the total NBS genes in sunflower are RNL genes which is consistent with other species, such as A. lyrata (2.5\%), A. thaliana (4.2\%), B. rapa (4.4\%), Capsella rubella $(4.7 \%)$ and T. salsuginea (5.7\%) [30]. Other results from this study that separate RNLs from the rest of the NBS genes include their highest average number of exons per gene and lowest average $K_{a} / K_{s}$ ratios values for the clade. This supports the hypothesis of high conservation and slow evolutionary rates among the RNL genes [86].

Sunflower NBS proteins identified in this study formed clades with reference proteins such as Pi36, P18, Rps2, VAT, RPG1, Gro1.4, RY-1, and N proteins, suggesting their homologous relationships (Figure S13). The sunflower TNL proteins are inferred to be orthologous to $S$. tuberosum nematode resistance protein (Gro1.4) [87], S. tuberosum subsp. andigena RY-1 (conferring resistance to potato virus Y) [88], and N. glutinosa Tobacco Mosaic Virus resistance (N) gene [89]. Similarly, sunflower CNL proteins are inferred to be orthologous to A. thaliana RPS2 (Resistant to P. syringae 2) [90], Cucumis melo VAT (resistance to Aphis gossypii) [91], H. annuus Pl8 [43], O. sativa Pi36 (conferring resistance to Blast fungus) [92], and H. vulgare subsp. vulgare RPG1 (conferring resistance to stem rust fungus) [93]. The BLAST investigation of sunflower NBS proteins with reference proteins available on http:/ / www.prgdb.org has shown some of them to be the possible homologs of the reference proteins (Table S7). Sunflower NBS proteins such as HanXRQChr13g0425411, HanXRQChr13g0425361, and HanXRQChr13g0425431 showed greater than $80 \%$ sequence identity to the H. annuus gene, Pl8 gene (CNL). The Pl8 gene is involved in conferring resistance to $P$. halstedii, a causative agent to downy mildew [43]. HanXRQChr04g0123041, belonging to the NL group has shown homology to L. esculentum EIX receptor 2 (Eix2), a gene that encodes receptor-like proteins (RLPs) involved in detecting ethylene-inducing xylanase, a fungus elicitor [94]. Other inferred homologs include HanXRQChr17g0552491 to MLA10, HanXRQChr13g0420141 to N, HanXRQChr17g0552491 to both MLA12 as well as MLA13, and HanXRQChr17g0552491 to Sr33. The MLA locus is highly polymorphic and encode allelic CNL type resistance proteins such as MLA1, MLA2, and MLA3 that confer resistance 
to barley powdery mildew fungus (Blumeria graminis f. sp. Hordei, Bgh) [95]. Another protein, Sr33, which belongs to the CNL type, confers resistance to a wheat stem rust pathogen, Puccinia graminis $f$. sp. tritici [96]. We were able to access expression profiles for only a few unique sunflower NBS proteins because of the duplicated names found for corresponding H. annuus r1.2 annotations compared to $H$. annuus $\mathrm{r} 1$ annotations. From the available expression data, it can be deduced that NBS genes can be expressed at a basal level with tissue specificity in unchallenged conditions [97]. In the expression dataset, most of the NBS genes were found to have a minimal to no expression value possibly as a result of low sequencing coverage, or their expression dependent on infection of pathogens or due to a pseudogenization, which was also noted by Frazier et al. 2016 [98]. Thus, detailed transcriptomic and proteomics studies are warranted to functionally characterize the sunflower NBS genes, particularly challenging the plant by various pests and pathogens through carefully crafted experimental designs.

\section{Conclusions}

We identified 352 NBS genes in sunflower and studied their clustering, phylogenetic relationships, gene homology and functional divergence. These genes formed clusters and showed structural conservation in signature domains and exon/intron architecture in CNL, TNL and RNL types of NBS genes. The RNLs belonged to the CNL-A clade, which in turn was found nested within the TNL clade, making both CNL and TNL clades paraphyletic. This warrants further rigorous analysis. All of the NBS-encoding genes have undergone purifying selection and available expression data have revealed their functional divergence. We confirmed homology of sunflower NBS genes to multiple previously characterized Pl8, LeEIX1, MLA10-13, Sr33 resistance genes. Further characterization of the NBS genes will help us to understand resistance pathways and to develop durable resistance necessary for crop improvement in sunflower, one of the major oilseed crops in the world.

Supplementary Materials: The following are available online at http:/ /www.mdpi.com/2073-4425/9/8/384/s1. Figure S1: Predicted protein domains in sunflower CNL protein sequences with number of LxxLxxLxx signatures in parentheses. Figure S2: Predicted protein domains in sunflower TNL protein sequences with the number of LxxLxxLxx signatures. Figure S3: Predicted protein domains in sunflower RNL protein sequences with number of LxxLxxLxx signatures. Figure S4: Predicted protein domains in sunflower NL protein sequences with the number of LxxLxxLxx signatures. Figure S5: Conserved domains of sunflower CNL genes predicted by MEME analysis. Figure S6: Conserved domains of sunflower TNL genes predicted by MEME analysis. Figure S7: Conserved domains of sunflower RNL genes predicted by MEME analysis. Figure S8: Chromosomal distribution of NBS genes in a sunflower $(n=17)$. Figure S9: Exon-intron architecture of the coding sequences of CNL genes in sunflower. Figure S10: Exon-intron architecture of the coding sequences of TNL genes in sunflower. Figure S11: Exon-intron architecture of the coding sequences of RNL genes in sunflower. Figure S12: Exon-intron architecture of the coding sequences of NL genes in sunflower. Figure S13: Maximum likelihood (ML) tree of the NBS amino acid sequences of the CNL, TNL and RNL genes from sunflower along with those of previously characterized CNL, TNL and RPW8 type genes. Figure S14: Syntenic relationships between chromosomes of Arabidopsis and sunflower. Figure S15: Identified genes in different clusters showing differential expression on all tissues in sunflower. Table S1: List of NBS gene accessions, their type, number of LxxLxxLxx signatures, exon/introns number, protein sequence length, gene orientation, amino acid length and amino acid sequences. Table S2: List of NBS genes of sunflower with nuclear localization signal (NLS) peptides. Table S3. Conserved MEME motifs in sunflower CNL family of proteins. Table S4. Conserved MEME motifs in sunflower TNL family of proteins. Table S5. Conserved MEME motifs in sunflower RPW8 family of proteins. Table S6: List of genes with their clusters and chromosomal location. Table S7: BLAST result of NBS genes against reference genes of Plant Resistance Genes database (PRGdb; http: / / prgdb.org) with a cutoff E-value of 0.01. Supplementary File S1: The motif sequence logos in the sunflower CNL family of R proteins. Supplementary File S2: Sequence alignment of the NBS domains belonging to different groups in fasta format. Supplementary File S3: Newick files for phylogenetic trees shown in Figures 3-5. Supplementary File S4: BLASTP result of NBS domains of the genes identified in this study and those previously identified by Gedil et al. 2001 [61], Plocik et al. 2004 [40], and Radwan et al. 2008 [42]. Supplementary File S5: Identification and classification of NBS-encoding genes using current pipeline (this study) compared to those predicted by RGAugury pipeline, and a list of RLPs, RLKs and TM-CC proteins in sunflower.

Author Contributions: Identification and analyses of the NBS-encoding genes in sunflower genome were conducted by S.N., M.P.N. conceived and supervised the research project. M.P.N. also provided guidance to S.N. on drafting the original manuscript, and undertook substantial rewriting during the revision. E.J.A. assisted in data analysis and revision of the manuscript. A.N. used the RGAugury pipeline to compare the outcomes of our pipeline and helped revise the manuscript. 
Funding: This project was supported by the United States Department of Agriculture hatch project (SD00H469-13) to M.P.N.

Acknowledgments: We would like to thank three anonymous reviewers for their valuable reviews.

Conflicts of Interest: The authors declare no competing interests.

\section{References}

1. Baluška, F.; Mancuso, S. Signaling in Plants, Signaling and Communication in Plants; Springer: Berlin/Heidelberg, Germany, 2009.

2. Wang, J.; Pan, C.; Wang, Y.; Ye, L.; Wu, J.; Chen, L.; Zou, T.; Lu, G. Genome-wide identification of MAPK, MAPKK, and MAPKKK gene families and transcriptional profiling analysis during development and stress response in cucumber. BMC Genom. 2015, 16, 386. [CrossRef] [PubMed]

3. Andersen, E.; Ali, S.; Byamukama, E.; Yen, Y.; Nepal, M. Disease resistance mechanisms in plants. Genes 2018, 9, 339. [CrossRef] [PubMed]

4. Sekhwal, M.K.; Li, P.; Lam, I.; Wang, X.; Cloutier, S.; You, F.M. Disease resistance gene analogs (RGAs) in Plants. Int. J. Mol. Sci. 2015, 16, 19248-19290. [CrossRef] [PubMed]

5. Yu, J.; Tehrim, S.; Zhang, F.; Tong, C.; Huang, J.; Cheng, X.; Dong, C.; Zhou, Y.; Qin, R.; Hua, W.; et al. Genome-wide comparative analysis of NBS-encoding genes between Brassica species and Arabidopsis thaliana. BMC Genom. 2014, 15, 1-18. [CrossRef] [PubMed]

6. Jones, J.D.; Dangl, J.L. The plant immune system. Nature 2006, 444, 323-329. [CrossRef] [PubMed]

7. Zipfel, C. Pattern-recognition receptors in plant innate immunity. Curr. Opin. Immunol. 2008, 20, 10-16. [CrossRef] [PubMed]

8. Andolfo, G.; Ercolano, M.R. Plant innate immunity multicomponent model. Front. Plant Sci. 2015, 6, 987. [CrossRef] [PubMed]

9. Kuang, H.; Woo, S.-S.; Meyers, B.C.; Nevo, E.; Michelmore, R.W. Multiple genetic processes result in heterogeneous rates of evolution within the major cluster disease resistance genes in lettuce. Plant Cell 2004, 16, 2870-2894. [CrossRef] [PubMed]

10. Vergne, E.; Grand, X.; Ballini, E.; Chalvon, V.; Saindrenan, P.; Tharreau, D.; Notteghem, J.-L.; Morel, J.-B. Preformed expression of defense is a hallmark of partial resistance to rice blast fungal pathogen Magnaporthe oryzae. BMC Plant Biol. 2010, 10, 206. [CrossRef] [PubMed]

11. Osuna-Cruz, C.M.; Paytuvi-Gallart, A.; Di Donato, A.; Sundesha, V.; Andolfo, G.; Aiese Cigliano, R.; Sanseverino, W.; Ercolano, M.R. PRGdb 3.0: A comprehensive platform for prediction and analysis of plant disease resistance genes. Nucleic Acids Res. 2017, 46, D1197-D1201. [CrossRef] [PubMed]

12. Gururani, M.A.; Venkatesh, J.; Upadhyaya, C.P.; Nookaraju, A.; Pandey, S.K.; Park, S.W. Plant disease resistance genes: Current status and future directions. Physiol. Mol. Plant Pathol. 2012, 78, 51-65. [CrossRef]

13. Shao, Z.-Q.; Xue, J.-Y.; Wu, P.; Zhang, Y.-M.; Wu, Y.; Hang, Y.-Y.; Wang, B.; Chen, J.-Q. Large-scale analyses of angiosperm nucleotide-binding site-leucine-rich repeat (NBS-LRR) genes reveal three anciently diverged classes with distinct evolutionary patterns. Plant Physiol. 2016. [CrossRef] [PubMed]

14. Meyers, B.C.; Kozik, A.; Griego, A.; Kuang, H.; Michelmore, R.W. Genome-wide analysis of NBS-LRR-encoding genes in Arabidopsis. Plant Cell 2003, 15, 809-834. [CrossRef] [PubMed]

15. Shao, Z.-Q.; Zhang, Y.-M.; Hang, Y.-Y.; Xue, J.-Y.; Zhou, G.-C.; Wu, P.; Wu, X.-Y.; Wu, X.-Z.; Wang, Q.; Wang, B. Long-term evolution of nucleotide-binding site-leucine-rich repeat genes: Understanding gained from and beyond the legume family. Plant Physiol. 2014, 166, 217-234. [CrossRef] [PubMed]

16. Zheng, F.; Wu, H.; Zhang, R.; Li, S.; He, W.; Wong, F.-L.; Li, G.; Zhao, S.; Lam, H.-M. Molecular phylogeny and dynamic evolution of disease resistance genes in the legume family. BMC Genom. 2016, 17, 402. [CrossRef] [PubMed]

17. Lee, H.A.; Yeom, S.I. Plant NB-LRR proteins: Tightly regulated sensors in a complex manner. Brief Funct. Genom. 2015, 14, 233-242. [CrossRef] [PubMed]

18. Michelmore, R.W.; Christopoulou, M.; Caldwell, K.S. Impacts of resistance gene genetics, function, and evolution on a durable future. Annu. Rev. Phytopathol. 2013, 51, 291-319. [CrossRef] [PubMed]

19. Die, J.V.; Román, B.; Qi, X.; Rowland, L.J. Genome-scale examination of NBS-encoding genes in blueberry. Sci. Rep. 2018, 8, 3429. [CrossRef] [PubMed] 
20. Sharma, R.; Rawat, V.; Suresh, C. Genome-wide identification and tissue-specific expression analysis of nucleotide binding site-leucine rich repeat gene family in Cicer arietinum (kabuli chickpea). Genom. Data 2017, 14, 24-31. [CrossRef] [PubMed]

21. Kang, Y.J.; Kim, K.H.; Shim, S.; Yoon, M.Y.; Sun, S.; Kim, M.Y.; Van, K.; Lee, S.-H. Genome-wide mapping of NBS-LRR genes and their association with disease resistance in soybean. BMC Plant Biol. 2012, 12, 139. [CrossRef] [PubMed]

22. Nepal, M.P.; Benson, B.V. CNL Disease resistance genes in soybean and their evolutionary divergence. Evol. Bioinform. Online 2015, 11, 49-63. [CrossRef] [PubMed]

23. Nepal, M.P.; Andersen, E.J.; Neupane, S.; Benson, B.V. Comparative genomics of non-TNL Disease resistance genes from six plant species. Genes 2017, 8, 249. [CrossRef] [PubMed]

24. Neupane, S.; Ma, Q.; Mathew, F.M.; Varenhorst, A.J.; Andersen, E.J.; Nepal, M.P. Evolutionary divergence of TNL disease-resistant proteins in soybean (Glycine max) and common bean (Phaseolus vulgaris). Biochem. Genet. 2018, 56, 397-442. [CrossRef] [PubMed]

25. Monosi, B.; Wisser, R.J.; Pennill, L.; Hulbert, S.H. Full-genome analysis of resistance gene homologues in rice. Theor. Appl. Genet. 2004, 109, 1434-1477. [CrossRef] [PubMed]

26. Zhou, T.; Wang, Y.; Chen, J.Q.; Araki, H.; Jing, Z.; Jiang, K.; Shen, J.; Tian, D. Genome-wide identification of NBS genes in japonica rice reveals significant expansion of divergent non-TIR NBS-LRR genes. Mol. Genet. Genom. 2004, 271, 402-415.

27. Ameline-Torregrosa, C.; Wang, B.B.; O’Bleness, M.S.; Deshpande, S.; Zhu, H.; Roe, B.; Young, N.D.; Cannon, S.B. Identification and characterization of nucleotide-binding site-leucine-rich repeat genes in the model plant Medicago truncatula. Plant Physiol. 2008, 146, 5-21. [CrossRef] [PubMed]

28. Yang, S.; Zhang, X.; Yue, J.-X.; Tian, D.; Chen, J.-Q. Recent duplications dominate NBS-encoding gene expansion in two woody species. Mol. Genet. Genom. 2008, 280, 187-198. [CrossRef] [PubMed]

29. Lozano, R.; Ponce, O.; Ramirez, M.; Mostajo, N.; Orjeda, G. Genome-wide identification and mapping of NBS-encoding resistance genes in Solanum tuberosum group phureja. PLoS ONE 2012, 7, e34775. [CrossRef] [PubMed]

30. Zhang, Y.M.; Shao, Z.Q.; Wang, Q.; Hang, Y.Y.; Xue, J.Y.; Wang, B.; Chen, J.Q. Uncovering the dynamic evolution of nucleotide-binding site-leucine-rich repeat (NBS-LRR) genes in Brassicaceae. J. Integr. Plant Biol. 2016, 58, 165-177. [CrossRef] [PubMed]

31. Andersen, E.J.; Ali, S.; Reese, R.N.; Yen, Y.; Neupane, S.; Nepal, M.P. Diversity and evolution of disease resistance genes in Barley (Hordeum vulgare L.). Evol. Bioinform. Online 2016, 12, 99. [CrossRef] [PubMed]

32. Andersen, E.J.; Nepal, M.P. Genetic diversity of disease resistance genes in foxtail millet (Setaria italica L.). Plant Gene 2017, 10, 8-16. [CrossRef]

33. Wan, H.; Yuan, W.; Bo, K.; Shen, J.; Pang, X.; Chen, J. Genome-wide analysis of NBS-encoding disease resistance genes in Cucumis sativus and phylogenetic study of NBS-encoding genes in Cucurbitaceae crops. BMC Genom. 2013, 14, 109. [CrossRef] [PubMed]

34. Xiang, L.; Liu, J.; Wu, C.; Deng, Y.; Cai, C.; Zhang, X.; Cai, Y. Genome-wide comparative analysis of NBS-encoding genes in four Gossypium species. BMC Genom. 2017, 18, 292. [CrossRef] [PubMed]

35. Li, P.; Quan, X.; Jia, G.; Xiao, J.; Cloutier, S.; You, F.M. RGAugury: A pipeline for genome-wide prediction of resistance gene analogs (RGAs) in plants. BMC Genom. 2016, 17, 852. [CrossRef] [PubMed]

36. Kane, N.C.; Rieseberg, L.H. Selective sweeps reveal candidate genes for adaptation to drought and salt tolerance in common sunflower, Helianthus annuus. Genetics 2007, 175, 1823-1834. [CrossRef] [PubMed]

37. Fernández-Martínez, J.; Melero-Vara, J.; Muñoz-Ruz, J.; Ruso, J.; Domínguez, J. Selection of wild and cultivated sunflower for resistance to a new broomrape race that overcomes resistance of the $\mathrm{Or}_{5}$ gene. Crop Sci. 2000, 40, 550-555. [CrossRef]

38. Seiler, G. Wild annual Helianthus anomalus and H. deserticola for improving oil content and quality in sunflower. Ind. Crops Prod. 2007, 25, 95-100. [CrossRef]

39. Markell, S.; Harveson, R.; Block, C.; Gulya, T. Sunflower Disease Diagnostic Series; PP1727-19; North Dakota State University Extension Service Publisher: Fargo, ND, USA, 2005.

40. Plocik, A.; Layden, J.; Kesseli, R. Comparative analysis of NBS domain sequences of NBS-LRR disease resistance genes from sunflower, lettuce, and chicory. Mol. Phylogenet. Evol. 2004, 31, 153-163. [CrossRef]

41. Hewezi, T.; Mouzeyar, S.; Thion, L.; Rickauer, M.; Alibert, G.; Nicolas, P.; Kallerhoff, J. Antisense expression of a NBS-LRR sequence in sunflower (Helianthus annuus L.) and tobacco (Nicotiana tabacum L.): Evidence 
for a dual role in plant development and fungal resistance. Transgenic Res. 2006, 15, 165-180. [CrossRef] [PubMed]

42. Radwan, O.; Gandhi, S.; Heesacker, A.; Whitaker, B.; Taylor, C.; Plocik, A.; Kesseli, R.; Kozik, A.; Michelmore, R.W.; Knapp, S.J. Genetic diversity and genomic distribution of homologs encoding NBS-LRR disease resistance proteins in sunflower. Mol. Genet. Genom. 2008, 280, 111-125. [CrossRef] [PubMed]

43. Radwan, O.; Mouzeyar, S.; Nicolas, P.; Bouzidi, M. Induction of a sunflower CC-NBS-LRR resistance gene analogue during incompatible interaction with Plasmopara halstedii. J. Exp. Bot. 2004, 56, 567-575. [CrossRef] [PubMed]

44. Badouin, H.; Gouzy, J.; Grassa, C.J.; Murat, F.; Staton, S.E.; Cottret, L.; Lelandais-Brière, C.; Owens, G.L.; Carrère, S.; Mayjonade, B. The sunflower genome provides insights into oil metabolism, flowering and Asterid evolution. Nature 2017, 546, 148. [CrossRef] [PubMed]

45. Finn, R.D.; Clements, J.; Arndt, W.; Miller, B.L.; Wheeler, T.J.; Schreiber, F.; Bateman, A.; Eddy, S.R. HMMER web server: 2015 update. Nucleic Acids Res. 2015, 43, W30-W38. [CrossRef] [PubMed]

46. Jones, P.; Binns, D.; Chang, H.-Y.; Fraser, M.; Li, W.; McAnulla, C.; McWilliam, H.; Maslen, J.; Mitchell, A.; Nuka, G. InterProScan 5: Genome-scale protein function classification. Bioinformatics 2014, 30, 1236-1240. [CrossRef] [PubMed]

47. Finn, R.D.; Bateman, A.; Clements, J.; Coggill, P.; Eberhardt, R.Y.; Eddy, S.R.; Heger, A.; Hetherington, K.; Holm, L.; Mistry, J. Pfam: The protein families database. Nucleic Acids Res. 2013, 42, D222-D231. [CrossRef] [PubMed]

48. Delorenzi, M.; Speed, T. An HMM model for coiled-coil domains and a comparison with PSSM-based predictions. Bioinformatics 2002, 18, 617-625. [CrossRef] [PubMed]

49. Bailey, T.L.; Elkan, C. Fitting a mixture model by expectation maximization to discover motifs in bipolymers. Proc. Int. Conf. Intell. Syst. Mol. Biol. 1994, 2, 28-36. [PubMed]

50. Emanuelsson, O.; Brunak, S.; von Heijne, G.; Nielsen, H. Locating proteins in the cell using TargetP, SignalP and related tools. Nat. Protoc. 2007, 2, 953-971. [CrossRef] [PubMed]

51. Ba, A.N.N.; Pogoutse, A.; Provart, N.; Moses, A.M. NLStradamus: A simple Hidden Markov Model for nuclear localization signal prediction. BMC Bioinform. 2009, 10, 202.

52. Thompson, J.D.; Higgins, D.G.; Gibson, T.J. CLUSTAL W: Improving the sensitivity of progressive multiple sequence alignment through sequence weighting, position-specific gap penalties and weight matrix choice. Nucleic Acids Res. 1994, 22, 4673-4680. [CrossRef] [PubMed]

53. Edgar, R.C. MUSCLE: Multiple sequence alignment with high accuracy and high throughput. Nucleic Acids Res. 2004, 32, 1792-1797. [CrossRef] [PubMed]

54. Kearse, M.; Moir, R.; Wilson, A.; Stones-Havas, S.; Cheung, M.; Sturrock, S.; Buxton, S.; Cooper, A.; Markowitz, S.; Duran, C. Geneious Basic: An integrated and extendable desktop software platform for the organization and analysis of sequence data. Bioinformatics 2012, 28, 1647-1649. [CrossRef] [PubMed]

55. Kumar, S.; Stecher, G.; Tamura, K. MEGA7: Molecular Evolutionary Genetics Analysis version 7.0 for bigger datasets. Mol. Biol. Evol. 2016, 33, 1870-1874. [CrossRef] [PubMed]

56. Letunic, I.; Bork, P. Interactive tree of life (iTOL) v3: An online tool for the display and annotation of phylogenetic and other trees. Nucleic Acids Res. 2016, 44, W242-W245. [CrossRef] [PubMed]

57. Jupe, F.; Pritchard, L.; Etherington, G.J.; MacKenzie, K.; Cock, P.J.; Wright, F.; Sharma, S.K.; Bolser, D.; Bryan, G.J.; Jones, J.D. Identification and localisation of the NB-LRR gene family within the potato genome. BMC Genom. 2012, 13, 75. [CrossRef] [PubMed]

58. Rozas, J.; Ferrer-Mata, A.; Sánchez-DelBarrio, J.C.; Guirao-Rico, S.; Librado, P.; Ramos-Onsins, S.E.; Sánchez-Gracia, A. DnaSP 6: DNA sequence polymorphism analysis of large data sets. Mol. Biol. Evol. 2017, 34, 3299-3302. [CrossRef] [PubMed]

59. Soderlund, C.; Bomhoff, M.; Nelson, W.M. SyMAP v3. 4: A turnkey synteny system with application to plant genomes. Nucleic Acids Res. 2011, 39, e68. [CrossRef] [PubMed]

60. Howe, E.A.; Sinha, R.; Schlauch, D.; Quackenbush, J. RNA-Seq analysis in MeV. Bioinformatics 2011, 27, 3209-3210. [CrossRef] [PubMed]

61. Gedil, M.A.; Slabaugh, M.B.; Berry, S.; Johnson, R.; Michelmore, R.; Miller, J.; Gulya, T.; Knapp, S.J. Candidate disease resistance genes in sunflower cloned using conserved nucleotide-binding site motifs: Genetic mapping and linkage to the downy mildew resistance gene Pl1. Genome 2001, 44, 205-212. [CrossRef] [PubMed] 
62. Ming, R.; Hou, S.; Feng, Y.; Yu, Q.; Dionne-Laporte, A.; Saw, J.H.; Senin, P.; Wang, W.; Ly, B.V.; Lewis, K.L. The draft genome of the transgenic tropical fruit tree papaya (Carica papaya Linnaeus). Nature 2008, 452, 991. [CrossRef] [PubMed]

63. Wu, J.; Zhu, J.; Wang, L.; Wang, S. Genome-wide association study identifies NBS-LRR-encoding genes related with anthracnose and common bacterial blight in the common Bean. Front. Plant Sci. 2017, 8, 1398. [CrossRef] [PubMed]

64. Lozano, R.; Hamblin, M.T.; Prochnik, S.; Jannink, J.L. Identification and distribution of the NBS-LRR gene family in the Cassava genome. BMC Genom. 2015, 16, 360. [CrossRef] [PubMed]

65. Guo, Y.-L.; Fitz, J.; Schneeberger, K.; Ossowski, S.; Cao, J.; Weigel, D. Genome-wide comparison of nucleotide-binding site-leucine-rich repeat-encoding genes in Arabidopsis. Plant Physiol. 2011, 157, 757-769. [CrossRef] [PubMed]

66. Mun, J.-H.; Yu, H.-J.; Park, S.; Park, B.-S. Genome-wide identification of NBS-encoding resistance genes in Brassica rapa. Mol. Genet. Genom. 2009, 282, 617-631. [CrossRef] [PubMed]

67. Christie, N.; Tobias, P.A.; Naidoo, S.; Külheim, C. The Eucalyptus grandis NBS-LRR gene family: Physical clustering and expression hotspots. Front. Plant Sci. 2016, 6, 1238. [CrossRef] [PubMed]

68. Hao, W.; Collier, S.M.; Moffett, P.; Chai, J. Structural basis for the interaction between the potato virus $X$ resistance protein (Rx) and its cofactor Ran GTPase-activating protein 2 (RanGAP2). J. Biol. Chem. 2013, 288, 35868-35876. [CrossRef] [PubMed]

69. Kohler, A.; Rinaldi, C.; Duplessis, S.; Baucher, M.; Geelen, D.; Duchaussoy, F.; Meyers, B.C.; Boerjan, W.; Martin, F. Genome-wide identification of NBS resistance genes in Populus trichocarpa. Plant Mol. Biol. 2008, 66, 619-636. [CrossRef] [PubMed]

70. Schumann, N.; Navarro-Quezada, A.; Ullrich, K.; Kuhl, C.; Quint, M. Molecular evolution and selection patterns of plant F-box proteins with C-terminal kelch repeats. Plant Physiol. 2011, 155, 835-850. [CrossRef] [PubMed]

71. Afzal, A.J.; Wood, A.J.; Lightfoot, D.A. Plant receptor-like serine threonine kinases: Roles in signaling and plant defense. Mol. Plant-Microbe Interact. 2008, 21, 507-517. [CrossRef] [PubMed]

72. Gómez-Gómez, L.; Boller, T. Flagellin perception: A paradigm for innate immunity. Trends Plant Sci. 2002, 7, 251-256. [CrossRef]

73. Zipfel, C.; Kunze, G.; Chinchilla, D.; Caniard, A.; Jones, J.D.; Boller, T.; Felix, G. Perception of the bacterial PAMP EF-Tu by the receptor EFR restricts Agrobacterium-mediated transformation. Cell 2006, 125, 749-760. [CrossRef] [PubMed]

74. Macho, A.P.; Zipfel, C. Plant PRRs and the activation of innate immune signaling. Mol. Cell 2014, 54, $263-272$. [CrossRef] [PubMed]

75. Song, W.-Y.; Wang, G.-L.; Chen, L.-L.; Kim, H.-S.; Pi, L.-Y.; Holsten, T.; Gardner, J.; Wang, B.; Zhai, W.-X.; Zhu, L.-H. A receptor kinase-like protein encoded by the rice disease resistance gene, Xa21. Science 1995, 270, 1804-1806. [CrossRef] [PubMed]

76. Godiard, L.; Sauviac, L.; Torii, K.U.; Grenon, O.; Mangin, B.; Grimsley, N.H.; Marco, Y. ERECTA, an LRR receptor-like kinase protein controlling development pleiotropically affects resistance to bacterial wilt. Plant J. 2003, 36, 353-365. [CrossRef] [PubMed]

77. Jeong, S.; Trotochaud, A.E.; Clark, S.E. The Arabidopsis CLAVATA2 gene encodes a receptor-like protein required for the stability of the CLAVATA1 receptor-like kinase. Plant Cell 1999, 11, 1925-1933. [CrossRef] [PubMed]

78. Kruijt, M.; Kip, D.J.; Joosten, M.H.; Brandwagt, B.F.; de Wit, P.J. The Cf-4 and Cf-9 resistance genes against Cladosporium fulvum are conserved in wild tomato species. Mol. Plant-Microbe Interact. 2005, 18, 1011-1021. [CrossRef] [PubMed]

79. Friedman, A.R.; Baker, B.J. The evolution of resistance genes in multi-protein plant resistance systems. Curr. Opin. Genet. Dev. 2007, 17, 493-499. [CrossRef] [PubMed]

80. Qian, L.-H.; Zhou, G.-C.; Sun, X.-Q.; Lei, Z.; Zhang, Y.-M.; Xue, J.-Y.; Hang, Y.-Y. Distinct patterns of gene gain and loss: Diverse evolutionary modes of NBS-encoding genes in three Solanaceae crop species. G3 Genes Genomes Genet. 2017, 7, 1577-1585. [CrossRef] [PubMed]

81. Leister, D. Tandem and segmental gene duplication and recombination in the evolution of plant disease resistance genes. Trends Genet. 2004, 20, 116-122. [CrossRef] [PubMed] 
82. Sánchez, D.; Ganfornina, M.D.; Gutiérrez, G.; Marín, A. Exon-intron structure and evolution of the Lipocalin gene family. Mol. Biol. Evol. 2003, 20, 775-783. [CrossRef] [PubMed]

83. Zeng, L.; Zhang, Q.; Sun, R.; Kong, H.; Zhang, N.; Ma, H. Resolution of deep angiosperm phylogeny using conserved nuclear genes and estimates of early divergence times. Nat. Commun. 2014, 5, 4956. [CrossRef] [PubMed]

84. Bonardi, V.; Tang, S.; Stallmann, A.; Roberts, M.; Cherkis, K.; Dangl, J.L. Expanded functions for a family of plant intracellular immune receptors beyond specific recognition of pathogen effectors. Proc. Natl. Acad. Sci. USA 2011, 108, 16463-16468. [CrossRef] [PubMed]

85. Peart, J.R.; Mestre, P.; Lu, R.; Malcuit, I.; Baulcombe, D.C. NRG1, a CC-NB-LRR protein, together with N, a TIR-NB-LRR protein, mediates resistance against tobacco mosaic virus. Curr. Biol. 2005, 15, 968-973. [CrossRef] [PubMed]

86. Collier, S.M.; Hamel, L.-P.; Moffett, P. Cell death mediated by the N-terminal domains of a unique and highly conserved class of NB-LRR protein. Mol. Plant-Microbe Interact. 2011, 24, 918-931. [CrossRef] [PubMed]

87. Paal, J.; Henselewski, H.; Muth, J.; Meksem, K.; Menéndez, C.M.; Salamini, F.; Ballvora, A.; Gebhardt, C. Molecular cloning of the potato Gro1-4 gene conferring resistance to pathotype Ro1 of the root cyst nematode Globodera rostochiensis, based on a candidate gene approach. Plant J. 2004, 38, 285-297. [CrossRef] [PubMed]

88. Vidal, S.; Cabrera, H.; Andersson, R.A.; Fredriksson, A.; Valkonen, J.P. Potato gene $Y-1$ is an N gene homolog that confers cell death upon infection with potato virus Y. Mol. Plant-Microbe Interact. 2002, 15, 717-727. [CrossRef] [PubMed]

89. Levy, M.; Edelbaum, O.; Sela, I. Tobacco mosaic virus regulates the expression of its own resistance gene N. Plant Physiol. 2004, 135, 2392-2397. [CrossRef] [PubMed]

90. Katagiri, F.; Thilmony, R.; He, S.Y. The Arabidopsis thaliana-Pseudomonas syringae interaction. Arabidopsis Book 2002, 1, e0039. [CrossRef] [PubMed]

91. Pitrat, M.; Maestro, C.; Ferriere, C.; Ricard, M.; Alvarez, J. Resistance to Aphis gossypii in Spanish melon (Cucumis melo). Cucurbit. Genet. Coop. Rep. 1988, 11, 50-51.

92. Liu, X.; Lin, F.; Wang, L.; Pan, Q. The in silico map-based cloning of Pi36, a rice coiled-coil-nucleotide-binding site-leucine-rich repeat gene that confers race-specific resistance to the blast fungus. Genetics 2007, 176, 2541-2549. [CrossRef] [PubMed]

93. Sallam, A.H.; Tyagi, P.; Brown-Guedira, G.; Muehlbauer, G.J.; Hulse, A.; Steffenson, B.J. Genome-wide association mapping of stem rust resistance in Hordeum vulgare subsp. spontaneum. G3 Genes Genomes Genet. 2017, 7, 3491-3507. [CrossRef] [PubMed]

94. Ron, M.; Avni, A. The receptor for the fungal elicitor ethylene-inducing xylanase is a member of a resistance-like gene family in tomato. Plant Cell 2004, 16, 1604-1615. [CrossRef] [PubMed]

95. Bai, S.; Liu, J.; Chang, C.; Zhang, L.; Maekawa, T.; Wang, Q.; Xiao, W.; Liu, Y.; Chai, J.; Takken, F.L. Structure-function analysis of barley NLR immune receptor MLA10 reveals its cell compartment specific activity in cell death and disease resistance. PLoS Pathog. 2012, 8, e1002752. [CrossRef] [PubMed]

96. Casey, L.W.; Lavrencic, P.; Bentham, A.R.; Cesari, S.; Ericsson, D.J.; Croll, T.; Turk, D.; Anderson, P.A.; Mark, A.E.; Dodds, P.N. The CC domain structure from the wheat stem rust resistance protein Sr33 challenges paradigms for dimerization in plant NLR proteins. Proc. Natl. Acad. Sci. USA 2016, 113, 12856-12861. [CrossRef] [PubMed]

97. Hammond-Kosack, K.E.; Jones, J.D. Plant disease resistance genes. Annu. Rev. Plant Biol. 1997, 48, 575-607. [CrossRef] [PubMed]

98. Frazier, T.P.; Palmer, N.A.; Xie, F.; Tobias, C.M.; Donze-Reiner, T.J.; Bombarely, A.; Childs, K.L.; Shu, S.; Jenkins, J.W.; Schmutz, J. Identification, characterization, and gene expression analysis of nucleotide binding site (NB)-type resistance gene homologues in switchgrass. BMC Genom. 2016, 17, 892. [CrossRef] [PubMed]

(C) 2018 by the authors. Licensee MDPI, Basel, Switzerland. This article is an open access article distributed under the terms and conditions of the Creative Commons Attribution (CC BY) license (http:/ / creativecommons.org/licenses/by/4.0/). 